Dr. sci. Nevzet Veladžić

\title{
Specifičnost Max Weberovog metodološkog pristupa znanosti
}

Sažetak

Max Weber smatra da su društveni fenomeni $i$ samo društvo nedvojbeno suviše kompleksni $d a$ bi se zadovoljio njihovim pojednostavljivanjem. Smjer u kojem idu njegova nastojanja je da svu složenost društvenih fenomena epistemološki analizira i objasni kako bi ih prikazao drukčijim nego što one laiku izgledaju. Takav pristup ima četiri dimenzije koje se u znanstvenim krugovima često nazivaju Weberovom metodološkom paradigmom, a koju čine: metoda izbora vrijednosti, metoda razumijevanja, metoda idealnih tipova $i$ teorija kauzalnog objašnjenja Weber drži da je nužno uspostaviti ispravan odnos kod izbora vrijednosti razlikujući pritom vrijednosnu relevantnost (value relevance) $i$ vrijednosnu neutralnost (value neutrality). Metoda razumijevanja treba da ponudi odgovor kako razumjeti društvenu zbilju, a to se, prema Weberu, može postići ukoliko zadovoljimo dva pravila: da događaje koje tumačimo smjestimo u kontekst u kojem nastaje $i$ drugo, da događaj koji tumačimo razumijevamo prema smislu koji mu sam akter događaja pridaje. Treća dimenzija je idealno-tipska metoda koja je, prema Weberu, analitička misaona konstrukcija istraživača koja pretpostavlja određena odstupanja od empirijske tačnosti i koju ne treba poistovjećivati sa povijesnom zbiljom. Četvrta dimenzija Weberovog metodološkog pristupa je multikauzalnost društvenih pojava. Prema ovom principu, složene društvene pojave u pravilu uvijek imaju više uzroka $i$ više posljedica

Iako se ne može tvrditi da je Weber izgradio zaseban metodološki sistem u kojem se kretao na putu shvaćanja društvene zbilje, njegova metodološka paradigma, koja je eliminatorna pretpostavka za razumijevanje Weberovog tumačenja društvenih fenomena poput kapitalizma, politike, moći, vlasti, države, religije, birokracije itd. čini ga prepoznatljivim. 
Ključne riječi: metodologija, znanstvena spoznaja, vrijednosti, metoda razumijevanja, idealni tipovi $i$ multikauzalnost.

\section{Uvod}

Max Weber (1864-1920.) je živio nepunih 56 godina. Iako je poticao iz bogate protestantske porodice (koja je ranije protjerana iz Salzburga) život ga nije nimalo poštedio iskušenja. U nekoliko narednih redaka pokušat ćemo oslikati porodični ambijent u kojem Weber živi navodeći samo one negativne utjecaje radi boljeg razumijevanja svega onog što je on učinio u relativno kratkom životnom razdoblju. Kao dijete boluje od meningitisa; u ranoj dobi njegova života prvo umire sestra Anna, potom Helena; konstantni sukob s ocem; u ranim tridesetim doživljava nervni slom i postaje ograničeno sposoban za rad, zbog čega nekoliko godina boravi u poznatim evropskim lječilištima; na političkom planu 1918. doživljava politički poraz na izborima za Reichstag; iste godine mu umire otac; brat Karl mu umire na ruskom frontu 1915, a nedugo poslije toga najmlađa sestra izvršila suicid; u zadnjoj godini života dolazi i kriza braka (odvojeni život od supruge Marianne Weber).

Kada se uzmu u obzir navedene činjenice, relativnu kratkoću njegovog života i izrazito dinamičan društveno politički život $u$ tadašnjoj Njemačkoj (politički angažman na kojeg je trošio dosta vremena), te Prvi svjetski rat, prosto ostajemo zadivljeni njegovim znanstvenim opusom.

Znanstveni rezultati Max Webera ${ }^{1}$ su impresivni i ostavili su dubok trag ne samo na evropsku, već ukupnu svjetsku znanost skoro jedno stoljeće nakon njegove smrti. Pored iznimno snažne motiviranosti i energije koju je posjedovao, Max Weber je izgradio vlastiti put u spoznavanju društvene stvarnosti, što je i tema ovog

\footnotetext{
1 Znanstveni radovi Max Webera: 1. «Metodologija drultvenih nauka», Globus, Zagreb, 1986. godine; 2.«Privreda i društvo», Tom I. Prosveta, Beograd, 1958; 3. «Privreda $i$ društvo», Tom II. Prosveta, Beograd, 1958; 4. «Vlast $i$ politika», Naklada Jesenski i Turk / Hrvatsko sociološko društvo, Zagreb, 1999: 5.«Sociologija religije», Kru-Zak, Zagreb, 2000.

6.«Protestantska etika $i$ duh kapitalizma», Naklada Jesenski i Turk/ Hrvatsko sociološko društvo, Zagreb,1998.
} 
našeg razmatranja. Na narednim stranicama pokušat ćemo predstaviti osnovne karakteristike Weberove metodologije u procesu spoznaje društvene stvarnosti.

\section{Metodološki pristup znanosti}

Pitanje metodologije sociologije i drugih društvenih znanosti su predmet Weberovog interesiranja u razdoblju kada je zbog bolesti morao da privremeno napusti univerzitetski posao i da se intenzivnije bavi liječenjem. S obzirom da su njegovi prvi radovi iz područja metodologije objavljeni u Archivu 1904. godine u formi eseja, tek od tog razdoblja pa do 1919. godine on se značajnije posvećuje pitanjima metodologije. Svojom historijskom sociologijom, koja tretira širok spektar sfera društvenog interesa i koja pokriva vremensko trajanje i do 2500 godina, iskazuje poseban metodološki pristup. Taj pristup se razlikuje od marxističkog, ali i drugih strukturalnih pristupa u historijskoj sociologiji, kao i filozofije historije općenito. Karakteristika njegovog pristupa je, uostalom kao i kod pristaša njemačke historijske škole i neokantovaca, da se ne mogu historijska značenja izvoditi iz univerzalnih zakonitosti i deduktivnih uopćavanja. Iz tog stava proizlazi da je deplasirano u takvim okvirima govoriti o primarnim pokretačima povijesti (svjetski duh, klasna borba i sl.). Prema ovakvom pristupu, povijest nema skrivenih značenja i nepotrebno je tragati za njima, jer historija društva nema apsolutne zakonitosti čija je istinitost jasna i ponovljiva. Po istom principu, Weber ne prihvaća, s jedne strane, puki subjektivizam kao što je pristup umjetničkom djelu, koji je jedinstven i neponovljiv čin i s druge, organsku analogiju u kojoj se društvo pojavljuje kao zatvoren i unutrašnje integriran sistem. Weber je svjestan da je teško govoriti o potpuno preciznoj i savršenoj teoriji, definiciji nekog dinamičkog društvenog fenomena koji egzistira jer konstantno dobiva nove kvalitativne i kvantitativne elemente, poput kulture koja uvijek iznova, pored tradicionalnih, poprima i elemente suvremene zbilje.

Da li možemo govoriti o Weberovoj metodologiji kao zasebnom metodološkom sistemu? Možda nam kao odgovor može poslužiti stav hrvatskog sociologa Duška Vrbana, koji kaže: «Može se 
reći da svoju metodologiju nije do kraja razradio na sustavan način, ali i da ju nije dosljedno primjenjivao u svojim radovima.»» ${ }^{2}$

Njegov metodološki pristup nije šire zapažen od strane intelektualne javnosti kako za njegovog života tako i nepune dvije decenije poslije. Tek će Talcot Parsons 1937. godine bitnije skrenuti pažnju na Weberovu 'teoriju društvenog djelovanja', što će utjecati na orijentaciju američke sociologije u smjeru korištenja onog dijela njegove metode koja se može primijeniti na razini pojedinačnog djelovanja (mikroakcijski pristup).

Uprkos ovakvom shvaćanju određenog broja autora, nitko ne može osporiti značaj Weberovog originalnog metodološkog pristupa, kako za samu metodologiju tako i za znanost općenito. Istina, ne možemo govoriti o njegovim precizno utvrđenim metodološkim postupcima, ali ništa manje nisu značajni ni temeljni principi istraživanja u sociologiji koje Weber ustanovljava, a koje često nazivamo Weberovom metodološkom paradigmom. Tu paradigmu čine četiri značajna elementa koja bitno određuju Weberov pristup historiji i sociologiji:

1. pitanje vrijednosti,

\section{2. metoda razumijevanja,}

\section{3. metoda idealnih tipova $\mathrm{i}$}

4. teorija uzročnog (kauzalnog) objašnjenja.

Navedena četiri svojstva njegove metodološke paradigme su osnova onoga što se $u$ literaturi označava kao Weberova 'interpretativna' ili 'razumijevajuća' sociologija i stoga smatramo značajnim da se osvrnemo na svako od ova četiri svojstva. ${ }^{3}$

a) Ono po čemu se Weber razlikuje od velikog broja svojih suvremenika koji pripadaju njemačkoj historijskoj školi kao i od

\footnotetext{
${ }^{2}$ Vrban Duško: Sociologija prava - uvod i izvršne osnove, Golden marketing Tehnička knjiga, Zagreb, 2006. str. 85.

${ }^{3} \mathrm{R}$. Holton $\mathrm{u}$ djelu Max Weber and the interpretative tradition objašnjava pojam interpretativne sociologije na temelju četiri metodološke postavke: vrijednosti, razumijevanje, ideal-tipovi i kauzalnog objašnjenja.
} 
predstavnika pozitivizma je stajalište da u humanističkim disciplinama, za razliku od prirodnih znanosti, je nužno prisutan odnos prema 'vrijednostima' (Wetbeziehung). Pitanje vrijednosti se može postaviti na dva načina: a) kao izbor vrijednosti koje su od važnosti za istraživanje historijske građe i b) kao pitanje osobnog preferiranja i motiva istraživača. Ustvari, radi se o pitanju vrijednosne relevantnosti (value relevance) i vrijednosne neutralnosti ili objektivnosti (value neutrality). Po Weberu ne postoje unaprijed zadani kriteriji za izbor vrijednosti koje bi imale važnost za društvena istraživanja: drugim riječima, to je stvar vlastitog izbora istraživača. Što se tiče objektivnosti (vrijednosne neutralnosti), Weber smatra da učenjački i nastavnički etos ne dopušta znanstveniku da promovira neke praktične ciljeve pa ni ideale koje osobno drži vrijednim.

$\mathrm{U}$ tom kontekstu, on povezuje znanstvenu objektivnost i vrijednosne stavove, pokazujući da mu «ništa ljudsko nije strano» jer je i sam uporno slijedio vlastita uvjerenja. Međutim, kada je riječ o znanstvenoj analizi pravi razliku empirijske spoznaje od vrijednosnih stavova.

Značaj pitanja vrijednosne neutralnosti govori i činjenica da je Weber ovom pitanju posvetio jedan esej, pod naslovom «Smisao vrijednosne neutralnosti socioloških $i$ ekonomskih znanosti», koji će kasnije, nešto prerađen, poslužiti kao uvod u raspravu u udruženju Verein für Sozialpolitik 1913. godine, čiji je Weber bio član. ${ }^{4}$ Pošto je ovaj prerađeni esej objavljen u vrijeme Prvog svjetskog rata (1917), Weber ima potrebu da upozori tadašnje intelektualne krugove Njemačke «da je obaveza intelektualaca da sačuvaju hladnu glavu nasuprot vladajućim idealima, čak i idealima veličanstva...» i naglašava da su «Njemačke ideje iz 1914. proizvod diletanata» ${ }^{5}$ Ratni ambijent utjecao je na univerzitetski intelektualni krug tako da je mnoge profesore, kako Weber smatra, uz njihovu volju regrutirao $\mathrm{u}$ propagandiste i proroke. Profesor ne bi smio zloupotrebljavati katedru kako bi propovijedao određenu političku viziju svijeta, osobna

\footnotetext{
${ }^{4}$ Tako prerađen tekst objavljen je u Logosu 1917. godine, vrijeme Prvog svjetskog rata. Prerada teksta sastojala se u izostavljanju njegova dijela koji je zanimao samo Verein, dok su proširena opća metodološka razmatranja.

${ }^{5}$ Weber Max: «Metodologija društvenih nauka», Drugo izdanje, Globus, Zagreb, 1989. str. 223
} 
vjerovanja i vrednovanja. Znanost je univerzalna vrijednost i nitko nema ekskluzivitet da je prisvaja ili da urušava njen ugled zarad vlastitih političkih nazora. «Profesor ne bi trebao postavljati zahtjev da kao profesor u svojoj naprtnjači nosi maršalsku palicu državnika (ili reformatora kulture), što on radi kad se služi okriljem katedre za izražavanje državničkih političkih (ili kulturnopolitičkih) sentimenata». ${ }^{6}$

b) Weber, za razliku od pozitivista, naglašava osobno iskustvo (Erlebnis) i subjektivnost kao značajnu dimenziju u procesu spoznaje društvenog djelovanja. Da bi spoznali određeni društveni fenomen, ili preciznije, da bi spoznali ulogu koju je protestantizam imao u nastanku i razvoju kapitalizma, Weber naglašava da je potrebno koristiti metodu koju on naziva «metodom razumijevanja». Po njemu, to je način spoznaje društvene zbilje. «Društvena znanost koju želimo promicati je znanost o zbilji»? ${ }^{7}$.

Odbacuje pokušaje da se iz sociologije izbaci povijesna metoda $\mathrm{u}$ ime pozitivističkog traganja za uzročnim zakonima. Stoga, prirodne i društvene znanosti ne mogu se redukcijom svesti na iste metode proučavanja i iste zakonitosti, prosto iz razloga što ljudsko ponašanja uvijek ima elemente nepredvidivosti, nelogičnosti i iracionalnosti. Isto tako, ljudsko ponašanje ne možemo svesti na vanjske manifestacije i vidljiva zbivanja, već se zahtjeva kontekstualno značenje. Weberov anti-pozitivizam temelji se na shvaćanju da u našim traženjima uvijek koristimo vlastite stavove, pa i predrasude. Uzimajući povijest kao izvor činjenica i znanja, njih biramo prema našim koncepcijama. «Nikada ne možemo koristiti svu kompleksnost povijesti, već iz nje vršimo odabir prema potrebi onog što želimo dokazati. Uz to, naše vrijednosti i vrijednosni stavovi uvijek su nam vodič u traganju za činjenicama, te moramo razumjeti ali i objasniti ono što je uzročno $u$ društvenom ponašanju, njegovom toku i posljedicama.» ${ }^{8}$ Kompleksnu historijsku pojavu ne možemo tumačiti u svoj njenoj složenosti, ali je možemo tumačiti na način da

\footnotetext{
${ }^{6}$ Weber Max: «Metodologija društvenih nauka», Drugo izdanje, Globus, Zagreb, 1989. str 17.

${ }^{7}$ Ibid.

${ }^{8}$ Kregar Josip, Duško Sekulić, Slaven Ravlić, Ksenija Grubišić: Uvod u sociologiju, Pravni fakultet Sveučilišta u Zagrebu, Zagreb, 2007. str. 170.
} 
je reduciramo na složenost koju razumijemo. Preciznije rečeno, u tumačenju svaki događaj smještamo u društveni kontekst u kojem nastaje, a razumijevamo ga tako što prepoznajemo unutarnje značenje koje ima pojedina pojava i smisao koji akter pripisuje svom ponašanju. Kao ilustraciju možemo se poslužiti primjerom Josipa Kregara kojeg navodi u svojoj knjizi Uvod u sociologiju (2007), koji kaže: «Recimo promatranje neke društvene situacije podrazumijeva razumijevanje - ako gledamo skupinu ljudi na nekom javnom mjestu, sama činjenica nije dovoljna bez znanja o tome čekaju li autobus, kupuju li nešto ili pak očekuju neki događaj.»»

U sociologiji metoda razumijevanja (Verstehen) jeste adekvatna objašnjenju (Erklären) u prirodnim znanostima. Oba navedena pristupa se mogu nadopunjavati i međusobno su više komplementarni nego isključivi principi u društvenoj analizi. Činjenice uvijek treba shvatiti u širem kontekstu značenja. Intuitivno razumijevanje određenog djelovanja postiže se kada možemo doživjeti to djelovanje $u$ mašti, $u$ njegovu emocionalnom i društvenom kontekstu. Shvaćanje subjektivnih značenja ponašanja ostvaruje se empatijom (Einfühlung) i interpretativnim objašnjenjem. Izravno razumijevanje značenja je rijetko i stoga, smatra Weber, je potrebno koristiti ove metodološke pristupe u istraživanja pojava.

«Mi hoćemo razumjeti zbilju života koja nas okružuje i u koju smo postavljeni u njezinoj posebnosti - odnose i kulturno značenje pojedinih njezinih pojava $u$ njihovim današnjim oblicima, $u$ jednu ruku, te razloge njihovog takvog a ne drugačijeg postojanja, u drugu ruku.» ${ }^{10}$

c) Idealni tipovi su, prema Weberu, misaone konstrukcije, odnosno uopćavanje koje postavlja istraživač, odstupajući manje ili više od empirijske tačnosti. I sam Weber naglašava da se «mora zahtijevati da se pri primjeni ove metode ne brka idealni tip i povijesna zbilja.» ${ }^{11}$ Idealno tipska metoda ima značenje ono koje joj sam Weber, kao njen tvorac, daje: «Idealni tip je... pokušaj da se povijesne jedinke ili njihovi pojedini sastavni dijelovi shvate $u$

\footnotetext{
${ }^{9}$ Ibid. Str. 170.

${ }^{10}$ Weber Max: «Metodologija društvenih nauka», Drugo izdanje, Globus, Zagreb, 1989. $\operatorname{str} 43$.

${ }^{11}$ Ibid. str. 78
} 
genetičkim pojmovima. Uzmimo na primjer pojmove «crkva» i «sekta»... ti pojmovi tada postaju idealno tipski, što znači da se ne pojavljuju ili da se pojavljuju samo odvojeno u punoj pojmovnoj čistoći. Ovdje, kao i drugdje, upravo taj pojam... odstupa od zbilje». ${ }^{12}$ Idealni tip je metoda koja je svojevrsni zaštitni znak Weberove metodološke koncepcije. Kao što smo već naglasili da se ne smije poistovjećivati sa pojavnom stvarnošću, već da se radi o konstrukciji mišljenja, odnosno sredstvu spoznaje kojim se znanstvenik služi. Konkretno govoreći, različiti fenomeni i smisao što im ga pridaju subjekti razlikuju se od slučaja do slučaja, ali sociologija kao znanost teži generalizaciji, a idealni tip je sredstvo kojim se ostvaruje taj proces generalizacije. Idealni tip valja razlikovati od drugih metoda apstrakcije: klasifikacije, tipologije i statističkog prosjeka. Ustvari, kako kaže Vjeran Katunarić, «idealan tip je još apstraktniji, čišći, 'idealniji', nestvarniji od apstraktnih kategorija kao što su, primjerice, društvene klase, prosječna zarada ili kapitalistička privreda.»» ${ }^{13}$ To je apstrakcija čiji se cilj sastoji u tome da beskonačnu raznolikost fenomena reducira na skup prikladnih i upotrebljivih kategorija. Heuristička upotrebljivost idealnog tipa ne može se definirati a priori: ona se provjerava $\mathrm{u}$ toku konkretnih analiza u kojima se posebni fenomeni mogu «mjeriti» po tome koliko su blizu ili daleko konceptu. Društveno djelovanje uvijek više podliježe vjerojatnosti nego izvjesnosti zbog toga što sama priroda društvenih odnosa stvara mogućnost odstupanja od očekivanog toka akcije. Idealni tip je sredstvo analize 'vjerojatnosti' da će akteri slijediti određeni pravac djelovanja radije nego neki drugi. Idealni tipovi se odnose na subjektivne elemente socijalnog života, jedinstvene i neponovljive elemente kulture koje pozitivistička socijalna znanost zanemaruje. Weber u svom objašnjenju ove metode ističe da se idealni tip «dobiva jednostranim isticanjem jednog ili pojedinih stajališta i ujedinjenjem čitavog niza difuznih, diskretnih, ovdje više, tamo manje prisutnih, mjestimice odsutnih pojedinačnih pojava, koje se, u skladu s jednostrano istaknutim stajalištima, sklapaju u pojmovnu sliku koja je u sebi jedinstvena. U svojoj pojmovnoj čistoći ta se slika ne može naći nigdje u zbilji; ona je utopija, a u povijesnom istraživanju postaje

\footnotetext{
${ }^{12}$ Ibid. str. 65.

${ }^{13}$ Katunarić Vjeran: Max Weber - Vlast i politika (Predgovor), Naklada Jesenski i Turk, Zagreb, 1999. str. 35
} 
zadaća da u svakom pojedinačnom slučaju utvrdi koliko je zbilja blizu ili daleko od tih idealnih slika, koliko, dakle, karakter privrednih odnosa nekog određenog grada nalikuje gradskoj privredi u pojmovnom smislu riječi. Ako se pažljivo koristi, taj pojam čini posebnu uslugu cilju istraživanja i predočavanja» 14

Kao što idealni tip nije opis stvarnosti, već se radi o mentalnoj konstrukciji koja uključuje bitna a ne prosječna svojstva fenomena, ovaj izraz isto tako ne implicira moralno stajalište. To je prije svega metodološki instrument koji olakšava razumijevanje društvenih pojava.

Pomoću ove idealno tipske metode Weber je izvršio svoje poznate analize vlasti (tradicionalne, karizmatske i racionalnolegalne), privrede (poduzeća, kapitalizma), religije (Crkva, sekte), organizacije (birokracija) i prava (formalno/supstantivno, racionalno/iracionalno).

Kako navodi Vjeran Katunarić, u predgovoru hrvatskog prijevoda Weberovog djela Vlast $i$ politika, metodu idealnog tipa, osim Webera, gotovo nitko je u sociologiji, historiografiji te političkim i pravnim znanostima nije primjenjivao, izuzev teoretičara prirodnog prava Gustava Radbrucha. Kao razloge isti autor navodi: «Weber je idealno-tipskim opisom obuhvatio neobično velik broj fenomena društvenog djelovanja i oblika ustanova. Čini se da je sve bitno obuhvaćeno $\mathrm{i}$ da $\mathrm{u}$ međuvremenu teško mogu nastati novi društveni fenomeni koji zaslužuju da se otvori rubrika nekog novog idealnog tipa. Tako na primjer, pojava novih komunikacijskih tehnologija koje omogućuju umreženo komuniciranje među pojedincima $\mathrm{s}$ različitih strana svijeta $\mathrm{u}$ smislu temeljnih tipova društvenog djelovanja, kao i društvene strukture, ni nije nova pojava. Nove su tehničke mogućnosti da se ostvare neke od kombinacija tipova društvenog djelovanja. Dakako, ni motivi takvog novog povezivanja ne mogu biti drukčiji od motiva starog povezivanja (prijateljstvo, poslovanje, političko ili slično interesno udruživanje

${ }^{14}$ Ibid. str. 62. 
itd.) Dakle, Weber je na neki način «pokrio» glavne mogućnosti opisa fenomena...» 15

d) Za razliku od Marxa, Spencera i Durkheima koji su tragali za univerzalnim zakonitostima društvenog razvoja, Weber razvija teoriju uzročnog (kauzalnog) objašnjenja u sociologiji. Glavna karakteristika ove teorije je «multikauzalnost»: složene društvene pojave nikada nemaju samo jedan uzrok i jednu posljedicu, u principu, uvijek više uzroka i posljedica. Prema Weberu, ljudsko ponašanje nije nepredvidljivo, a metafizički koncept slobode volje ne bi ničemu služio u sociologiji. Pri tome je svjestan teškoća u otkrivanju uzroka društvenih pojava zbog velike složenosti društvenih situacija. U jednoj polemičkoj raspravi koja se odvijala u časopisu Archiv, on navodi: «Zajedno s pravnom teorijom pitamo prije svega kako je... moguće pripisivanje nekog konkretnog 'učinka' pojedinom 'uzroku' i kako je to izvedivo unatoč činjenici da je uistinu uvijek bezbrojnost uzročnih momenata uvjetovala nastanak pojedinog 'događaja' i da su svi ti pojedinačni uzročni momenti bili nužni za nastanak učinka $u$ njegovom konkretnom obliku?»» ${ }^{16}$

\section{Zaključak}

Iz navedenog vidimo da Weber ne prihvata determinizam društvenih procesa (poput marxističke teorije), već upućuje na vjerojatnost (probabilizam) odnosa mnogobrojnih uzroka i nekog učinka kojeg nazivamo posljedicom. U njegovom razmatranjima uzročnosti možemo primijetiti razliku između dva tipa uzročnih veza: a) povijesnih i b) socioloških. Shodno toj podjeli, u povijesnim događanjima postavljamo pitanja jesu li neki događaji bili nužni ili ne, $\mathrm{u}$ jednom izoliranom i neponovljivom značenju (npr. pucnjava pred dvorcem koja je dovela do revolucije 1848. godine). S druge strane, kod sociološkog tipa događanja radi se uzročnim vezama kojima se otkrivaju pravilnosti vezanih za duža vremenska razdoblja koristeći idealno tipsku metodu.

\footnotetext{
${ }^{15}$ Katunarić Vjeran: Max Weber - Vlast i politika (Predgovor), Naklada Jesenski i Turk, Zagreb, 1999. str. 35. i 36.

${ }^{16}$ Ibid. str. 65.
} 
Možemo zaključiti da Weberovo shvaćanje uzročnosti je multikauzalno, odnosno da uvijek postoji više uzroka koji su nužni u procesu stvaranja pojave i svi oni daju dizajn pojavi koju nazivamo posljedicom.

Na kraju, iako ne možemo govoriti o potpuno zaokruženom metodološkom sistemu navedene četiri metode su dale dodatnu dimenziju u Weberovim istraživačkim analizama, posebno u djelima «Protestantska etika $i$ duh kapitalizma», "Vlast $i$ politika» te "Privreda $i$ društvo». Metoda idealnih tipova, ranije rijetko korištena, Weber je dovodi do savršenstva. Uostalom, kao što su u razvoju metodologije dali doprinos svi veliki intelektualni umovi tako je i Weber svojim radom Metodologija društvenih nauka predstavio svoja razmišljanja kako spoznati složene društvene pojave i doći do istine. Svrha nauke je dolazak i spoznaja istine.

\section{Literatura}

1. WEBER, Max; «Metodologija drultvenih nauka», Globus, Zagreb, 1986.

2. WEBER, Max; «Privreda $i$ društvo», Tom I. Prosveta, Beograd, 1958

3. WEBER, Max; «Privreda i društvo», Tom II. Prosveta, Beograd, 1958

4. WEBER, Max; «Vlast i politika», Naklada Jesenski i Turk / Hrvatsko sociološko društvo, Zagreb, 1999:

5. WEBER, Max; «Sociologija religije», Kru-Zak, Zagreb, 2000.

6. WEBER Max: «Protestantska etika $i$ duh kapitalizma», Naklda Jesenski i Turk/ Hrvatsko sociološko društvo, Zagreb, 1998.

7. BENDIX, R., „The Comarative Analysis of Historical Change", Tavistok Publications, London, 1967.

8. BENDIX, R., Max Weber: „An intelectual portrait“, Doubleday \& Co, New York, 1962.

9. BLAU, Peter: Bereaucracy in Modern Society, 2nd edition, Random House, New York, 1971.

10. CLAUS, Offe; «Tocqueville,Weber i Adorno u Americi», Politička misao, Zagreb 2004 
11. DAMAŠKA, Mirjan: «The Faces of Justice», Yale University Press, 1986.

12. GURVITCH, Georges: Sociologija prava, Podgorica, 1997, godine

13. HABERMAS, Jürgen; "The Theory of Communicative Action», Volume One, Reason and the Rationalization of Society, Publisher by Heinemann, London, 1984.

14. HARALAMBOS, Michael / Martin Holborn; «Sociologija: teme i perspektive», Zagreb 2002.

15. HELD, David: Demokracija i globalni poredak, «Filip Višnjić», Beograd, 1997.

16. KALANJ, Rade; «Suvremenost klasične sociologije», Politička kultura, Zagreb, 2005.

17. KREGAR, Josip; «Nastanak predatorskog kapitalizma $i$ korupcija», Rifin, Zagreb, 1999.

18. KREGAR, Josip; D. Polšek, S. Ravlić; «Uvod u sociologiju», Pravni fakultet u Zagrebu, Zagreb, 2005.

19. KRONMAN, Anthony; "The Lost Lawyer», The Belknap Press of Harvard University Press, London, 1993.

20. LUHMAN, Niklas; «Legitimacija kroz proceduru», Zagreb 1992.

21. PUHOVSKI, Žarko; «Aporije weberove racionalizacije», Politička misao 3, Zagreb, 1985.

22. PUSIĆ, Eugen; «Društvena regulacija», Globus, Zagreb, 1989.

23. SICA, Alan (1990) «Weber, Irrationality, and Social Order», Unuversity of California Press, Berkeley-Los AngelesLondon, 1990.

24. TURNER, Stephen P. \& Regis A. Factor: Max Weber - The Lawyer as Social Thinker, Routledge, London and New York, 1990

25. VRBAN, Duško; «Država i pravo», Zagreb, 2006. 
Dr. sci. Nevzet Veladžić, SENIOR LUCTURER

\section{SPECIFIC QUALITY OF MAX WEBER'S METHODOLOGICAL APPROACH TO SCIENCE}

SUMMARY

Max Weber believes that social phenomenon and society in general represent complex concepts which can not be rationalised without significant effort. He aims to provide an epistemological analysis and explanation of complex social phenomenon in order they can be correctly understood. Such approach consists of four distinctive dimensions which are in scientific circles often described as Weber's methodological paradigm: method of value selection, method of comprehension, method of ideal types and theory explanation of causality.

Weber states that it is obligatory to establish correct relation regarding value selection differentiating between value relevance and value neutrality. Method of comprehension attempts to understand social reality which can be accomplished if we complete two objectives: we must place events in their proper context and understand them according to meaning of present subject. Third dimension is method of ideal types which represents explorer's analytical contemplative construction which must not be identified with historical reality and contains certain variation from empirical reality. Fourth dimension is multiple social events causality. Complex social events have in general multiple causes and multiple consequences according to this principle.

Although we can not affirm that Weber built unique methodological system, his methodological paradigm as an essencial presumption for understanding Weber's social phenomenon interpretation makes him recognizable.

Key words: methodology, scientific perception, values, method of comprehension, ideal types and multiple causality 


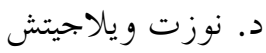

\section{خصوصية منهج تناول ماكس فيبر (Max Weber) للمعرفة}

\section{خلاصة البحث}

يعتقد ماكس فيبر أنّ الظواهر الاجتماعية وحتى المُتمع بلا شك أكثر تعقيداً مِنْ أنْ يرضى بتبسيطها. محولات فيبر تتّهه إلى تحليل فلسفي وشرح لتعقيدات الظواهر الاجتماعية حتى يصوّرّها على الشكل المختلف محا تبدو لشخص غير مختصّ. هذا النوع من التناول له أربعة أبعاد معروفة في الأو ساط العلمية بِ"نموذج فيبر المنهجي" وهو مؤلف من: منهج اختيار القيم، منهج الفهم، منهج الأنماط المثالية ونظرية الشرح السيي. يعتقد فيبر أنه من الضروري إقامة علاقة صحيحة لدى اختيار القيمة مفرِّاً بين النسبة القيمية والحياد القيمي.

منهج الفهم يقدّم الجواب حول كيفية فهم الحالة الاجتماعية السائدة، ويمكن تحقيق ذلك إن طبّقنا قاعدتين: أ) أن نضع الحوادث التي نريد شرحها في السياق الذي تَحْدُثُ فيه، وبَ) أن نفهم الحادثة اليت نريد تفسيرها حسب المعنى الذي يقصده صانع تلك الحوادث. البعد الثالث هو منهج الأنماط المثالية وهو في نظر فيبر بناء الباحث التحليلي والفكري والذي يفترض بعض العدول عن الدقة الاختبارية والتي لا ينبغي قياسها على حوادث التاريخ. البعد الرابع في منهجية فيبر هو التعددية السببية للظواهر الاجتماعية. بناء على هذا المبدأ فإنّ الظو اهر الاجتماعية المعقّدة في الأصل لها أسباب ونتائج كثيرة.

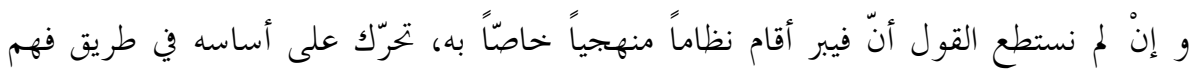
الحالة الاجتماعية السائدة، ولكن قياسه المنهجي والذي يعتبر فرضية حتمية لفهم شرحه للظو اهر الاجتماعية، مثل الرأسمالية والسياسة و القوّة و السلطة و الدولة و الدين و البيروقر اطية إلخ،

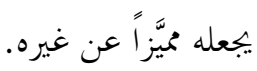

